\title{
Review Paper \\ An Overview of Antimicrobial Peptides as Anticancer Agents
}

\author{
Ali Ganji ${ }^{1,2} \odot$, Amir Mohammad Saeedi ${ }^{2} \oplus$, Ali Ghazavi ${ }^{3} \odot,{ }^{*}$ Ghasem Mosayebi ${ }^{1,2} \odot$ \\ 1. Molecular and Medicine Research Center, Arak University of Medical Sciences, Arak, Iran. \\ 2. Department of Immunology, School of Medicine, Arak University of Medical Sciences, Arak, Iran. \\ 3. Traditional and Complementary Medicine Research Center (TCMRC), Arak University of Medical Sciences, Arak, Iran.
}

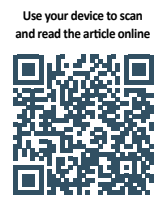

Crtation: Ganji A, Saeedi AM, Ghazavi A, Mosayebi Gh. [An Overview of Antimicrobial Peptides as Anticancer Agents (Persian)]. Journal of Arak University of Medical Sciences (JAMS). 2019; 22(4):2-15. https://doi.org/10.32598/JAMS.22.4.10

doi) https://doi.org/10.32598/JAMS.22.4.10

\section{(1) (1) (3)}

Article Info:

Received: 04 Nov 2018

Accepted: 12 Mar 2019

Available Online: 01 Oct 2019

Keywords:

Antimicrobial

Peptides (AMPs),

Anticancer Peptides

(ACPs), Cancer im-

munotherapy

\section{A B S TRACT}

Cancer is one of the leading causes of death worldwide. Thus, it is important to find newer, more selective, and more effective therapies for this disease. One of these methods that have attracted many researchers is using anticancer peptides regarding their specificity, lower side effects, and higher effectiveness on the cancer cells. One type of anticancer peptides is antimicrobial peptides. Although they have already been studied and introduced as potential agents to fight infectious diseases, only recently they have been used as a new way of cancer treatment. For decades, antimicrobial peptides have been considered a component of the native immune system; however, they can also be used as anticancer peptides due to their mechanisms and properties. This new therapeutic approach can provide a promising pathway for optimal cancer treatment with fewer side effects.

\section{Extended Abstract}

\section{Introduction}

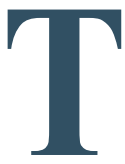

oday, finding a suitable, inexpensive, and simple treatment for various cancers is essential [4]. One of these strategies is the use of Antimicrobial Peptides (AMPs), which are part of the innate immune response to microbes [6-8]. AMPs can act against cancer cells through various mechanisms such as apoptosis, activation of the immune system, and so on [7, 9]. In this study, we reviewed some of the most important types of AMPs.

\section{Materials and Methods}

The papers published in English were searched in Springer, ScienceDirect, PubMed, and Google Scholar databases by using the following keywords: Antimicrobial peptides, Anticancer peptides, Cationic peptides, as well as AMP names.

\section{Results}

\section{AMPs with $\alpha$-helical structure}

LL-37 peptide is an antimicrobial agent derived from human cathelicidin [10]. Numerous studies have shown that

\section{* Corresponding Author:}

Ghasem Mosayebi, PhD.

Address: Department of Immunology, School of Medicine, Arak University of Medical Sciences, Arak, Iran.

Tel: +98 (918) 3495332

E-mail: ghasemmosayebi@arakmu.ac.ir 
LL-37 and its analogs increase toxicity in cancer cells, and some have pointed to its role in cancer progression and metastasis [11]. Melittin is a water-soluble, linear, cationic, hemolytic, and amphipathic polypeptide containing 26 amino acids [20]. The results suggest that the inhibitory effect of melittin on the migration of breast cancer cells may be related to the inhibition of the mTOR (The mammalian target of rapamycin) pathway [24].

Bovine Antimicrobial Peptides (BAMPs) in two types of BMAP-27 and BMAP-28 with one and two amino acid sequences have been isolated from bovine cathelicidin [27, 28]. Treatment with BMAP-28 in human cancer cells of U937 and K562 results in pore opening in the mitochondrial membrane and eventually release of cytochrome c leading to cell death or apoptosis [29].

Cecropin A and B are another type of AMPs isolated from the hemolymph of a giant silk moth [31]. The effect of cecropin B on human gastric carcinoma cell lines showed that by decreasing the external currents, it reduced the pore formation of the membrane channels [31]. Magainin, as a specific cytotoxic substance for cancer cells, has been isolated from the skin of African clawed frogs [35]. The findings have indicated that magainin II has specific cytotoxicity against cancer cells and can induce apoptosis [37].

Aurein peptide is another AMP found in the skin secretions of Australian frogs [41]. This peptide has moderate anticancer activity against 52 of the 54 cancer cell lines [41, 43]. Another AMP is gaegurin, which is isolated from the skin of a Korean frog [45], and some studies have shown that gaegurin 5 and gaegurin 6 have specific cytotoxic activity against neoplastic cells [46].

Buforin-I is a 39 amino acid AMP that was first isolated from the stomach tissue of an Asian frog [47]. Numerous studies have shown that buforin II and buforin IIb (a synthetic analog of buforin II), exhibit specific cytolytic activity against 62 cancer cell lines [51].

\section{AMPs with $\beta$-sheet structure}

Defensins are a group of cysteine- and arginine-rich cationic AMPs [52]. Xu et al. reported that the injection of $\alpha$-defensin-1 inhibited human lung adenocarcinoma cell growth in nude mice and induced their apoptosis [56]. Lactoferricin is a cationic AMP produced by the hydrolysis of lactoferrin [57]. Some studies have shown that bovine lactoferrin has great anticancer potential by activation of signaling pathways [58].
Another AMP is tachyplesin. In 2018, the combined effect of tachyplesin-I and cisplatin AMPs on tumor cells and normal human cells was studied. Results showed that their combined use reduced the effective cytotoxic dose and thus decreased non-specific toxicity [63].

\section{Discussion}

Although AMPs have been known for decades, it is only in the last decade that the study of their anticancer activities has increased, and they were referred to as Anticancer Peptides (ACPs). That is why we believe that in the coming years, the use of these peptides, due to their unique properties (influencing cancer cells), will be increased for the treatment of cancer, which is one of the greatest concerns of human society in the world. Another strategy is the combined use of peptides with conventional chemotherapeutic drugs, which reduces the cost of treatment, minimizes the problem of cancer resistance, and prevents its recurrence. Advances in the production of these peptides in a large-scale worldwide have made this treatment cheaper and more accessible to patients. However, there may be some limitations, such as the possible similarity of these peptides to their antigens or the stimulation of the immune system against these peptides. Finally, it can be said that these peptides have gone a long way in optimizing the treatment process for cancer and can provide a novel and less complicated treatment approach.

\section{Ethical Considerations}

\section{Compliance with ethical guidelines}

This study was extracted from a research proposal approved by the Research Ethics Committee of Arak University of Medical Sciences (Code: IRARAKMU1397.174).

\section{Funding}

This study was sponsored by the Deputy for Research and Technology of Arak University of Medical Sciences.

\section{Authors' contributions}

Study design, conceptualization, original draft preparation, and editing by Ali Ganji; Initial draft preparation and editing by Amir Mohammad Saeedi; Data gathering and editing by Ali Ghazavi; Conceptualization and review by Ghasem Mosayebi.

\section{Conflicts of interest}

The authors declare no conflict of interest. 


\section{Acknowledgements}

The authors would like to thank the Deputy for Research and Technology and the Molecular and Medicine Research

Center for their financial and spiritual support. 


\section{مرورى بر بيتيدهاى ضدميكروبى به عنوان عوامل ضدسرطان}

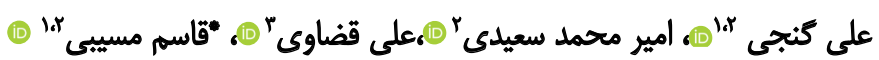

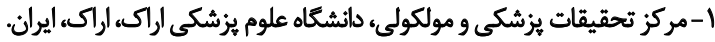

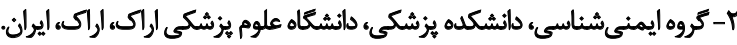

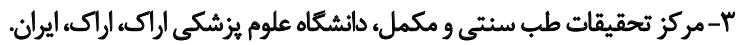

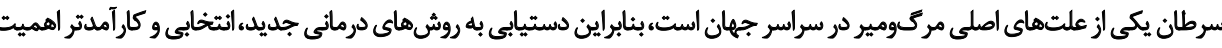

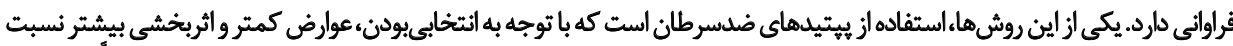

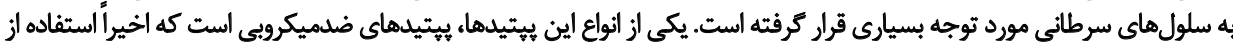

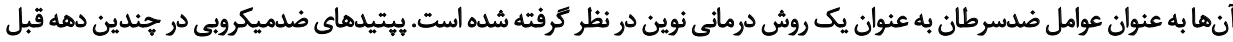

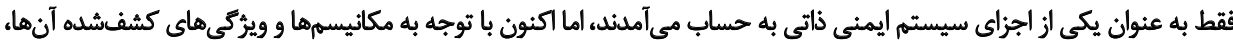

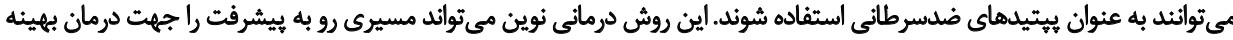

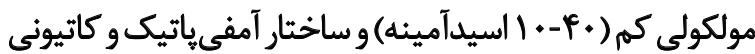

مقدمه

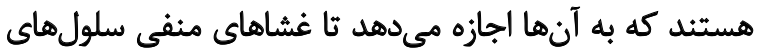

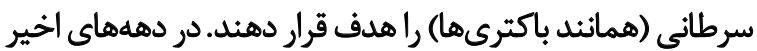

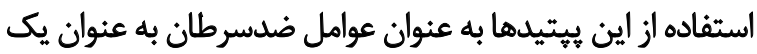

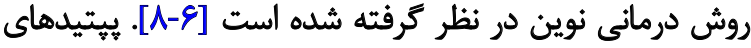

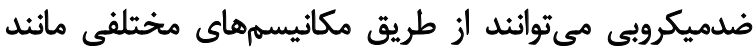

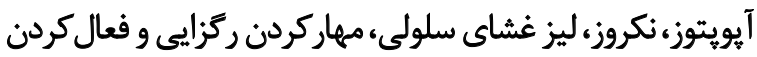

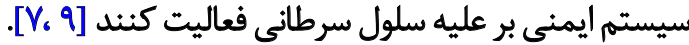
در اين مقاله مرورى، كروه جديدى از عوامل ضدسرطان ياني

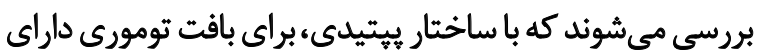

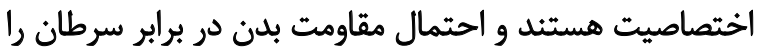

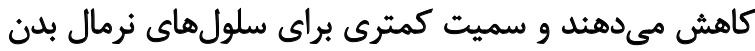

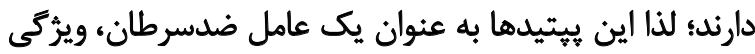

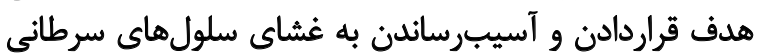

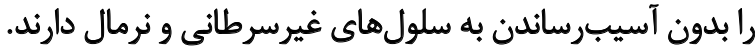

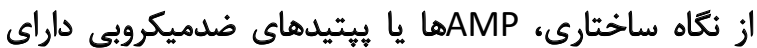

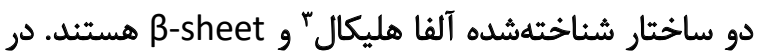
ياييًاه دادههاى AMP، بيش از صد نوع AMP با عنوان فعاليت

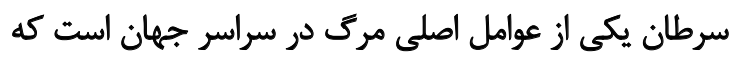

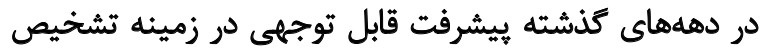

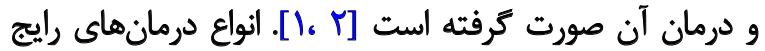

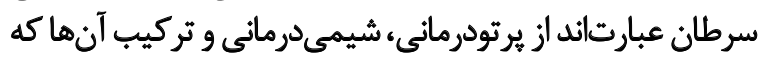

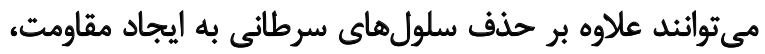

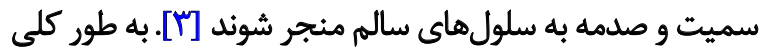

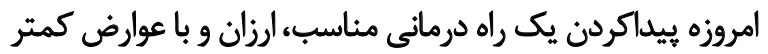

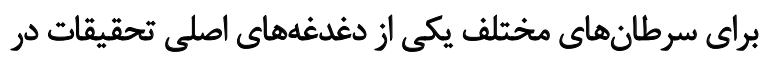

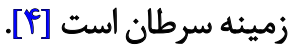

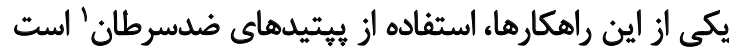

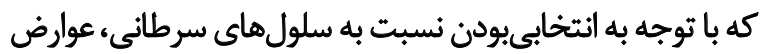

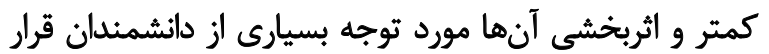

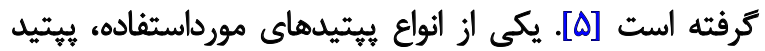

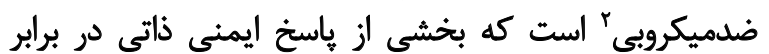

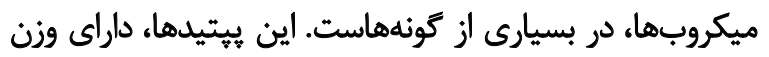

1. Anti Cancer Peptides (ACP)

2. Anti Microbial Peptides (AMP)

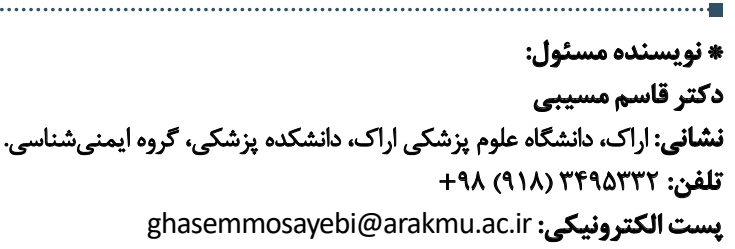


جدول ا. ليست بيتيدهاي ضدميكروبى به همراه توالى اسيدآميئه آنها

\begin{tabular}{|c|c|}
\hline نام ييتيد & توالى اسيدآمينه \\
\hline BMAP-YV & GRFKRFRKKFKKLFKKLSPVIPLLHL \\
\hline BMAP-YA & GGLRSLGRKILRAWKKYGPIIVPIIRI \\
\hline Cecropin A & KWKLFKKIEKVGQNIRDGIIKAGPAVAVVGQATQIAK \\
\hline Cecropin B & KWKVFKKIEKMGRNIRNGIVKAGPAIAVLGEAKAL \\
\hline LLYV & LLGDFFRKSKEKIGKEFKRIVQRIKDFLRNLVPRTES \\
\hline Magainin $Y$ & GIGKFLHSAKKFGKAFVGEIMNS \\
\hline Aurein & GLFDIIKKIAESF \\
\hline Gaegurin $\Delta$ & FLGALFKVASKVLPSVKCAITKKC \\
\hline Gaegurin $\&$ & FLPLLAGLAANFLPTIICFISYKC \\
\hline Buforin I & AGRGKQGGKVRAKAKTRSSRAGLQFPVGRVHRLLRKGNY \\
\hline Buforin II & TRSSRAGLQFPVGRVHRLLRK \\
\hline Mellitin & GIGAVLKVLTTGLPALISWIKRKRQQ \\
\hline HNP-1 & ACYCRIPACIAGERRYGTCIYQGRLWAFCC \\
\hline HNP-Y & CYCIPACIAGERRYGTCIYQGRLWAFCC \\
\hline HNP-Y & DCYCRIPACIAGERRYGTCIYQGRLWAFCC \\
\hline Lactoferricin & FKCRRWQWRMKKLGAPSITCVRRAF \\
\hline Tachyplesin I & KWCFRVCYRGICYRRCR \\
\hline
\end{tabular}

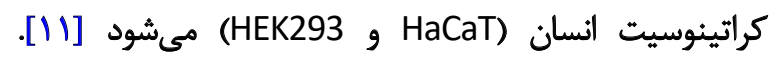

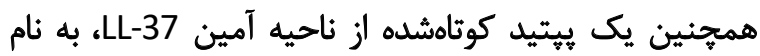

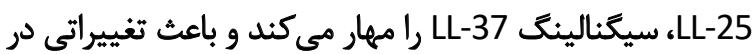

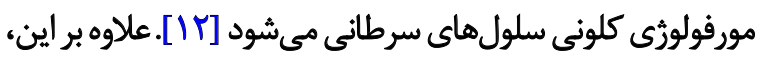

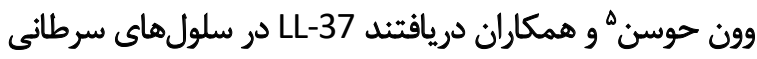
ريه انسان بيان شده و به عنوان عامل رشد عمل مي كند [11]].

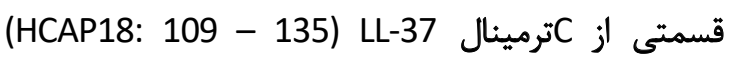

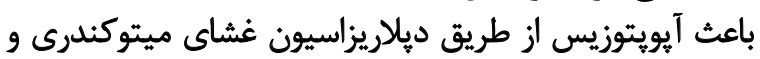

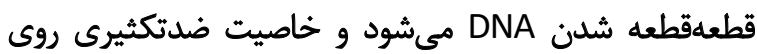
بسيارى از سرطانها ماند كارسينوم سلول سنكفرشي إنسي انسانى

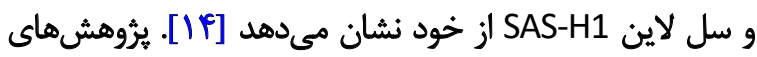

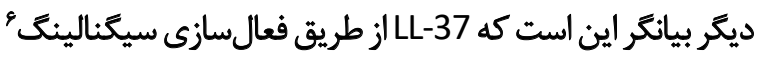

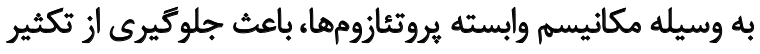

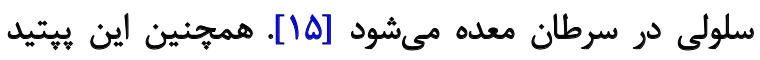

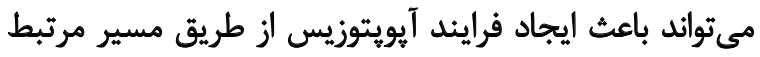

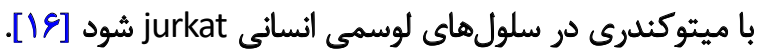

\section{Haussen}

6. Bone Morphogenic Protein (BMP)
بالقوه ضدتومورى مشخص شدهاند كه براي مشاهده ليست

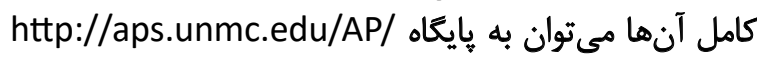

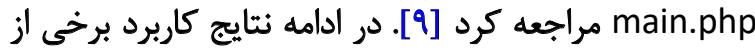

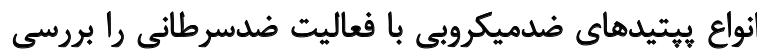
خواهيم كرد (جدول شماره 1).

$$
\text { يبيديدهاي ضدسر طانى آلفا هليكال }
$$

LL-M

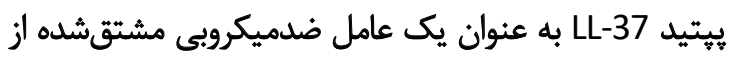

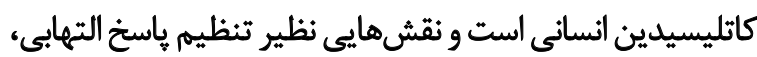

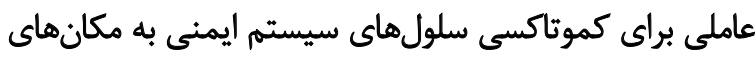

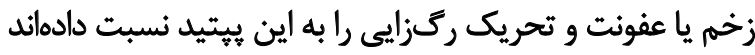

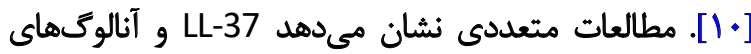

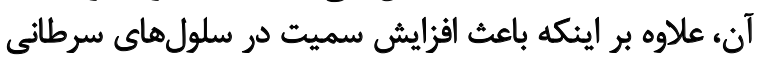

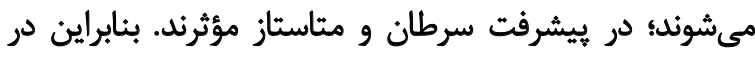

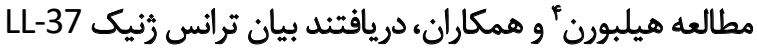

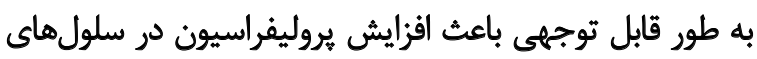

4. Heilborn 
خشك آن را تشكيل ميدهد. ناحيه N ترمينال آن عمدتاً

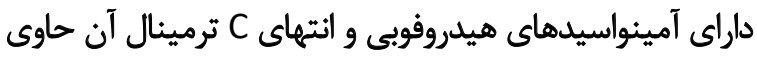

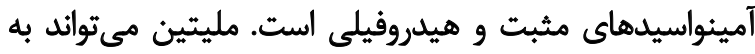

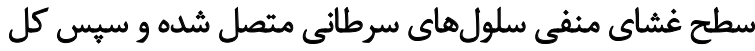

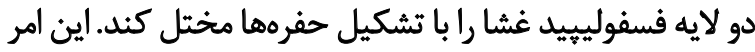

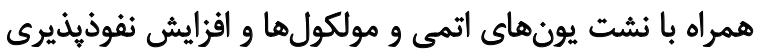

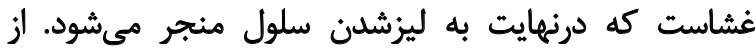

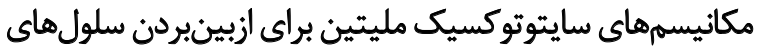

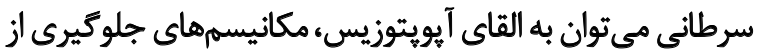

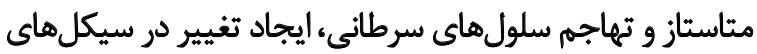

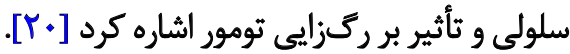

به علت فقدان نسبى انتخابيوبودن مليتين براى سلولهائ سرطانى،

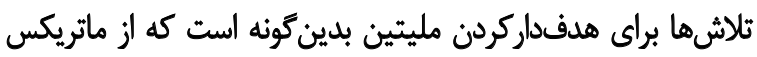

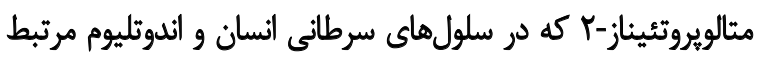

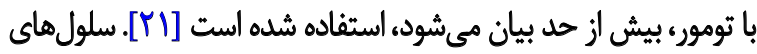
كارسينوم 145 ول 140

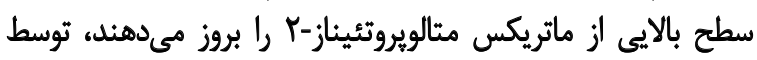

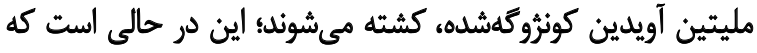

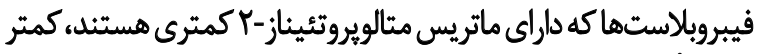

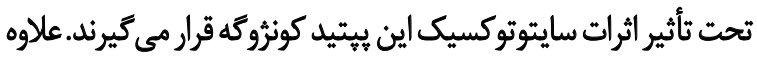

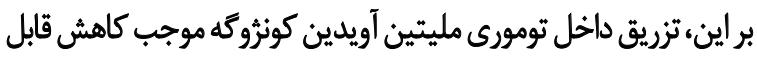

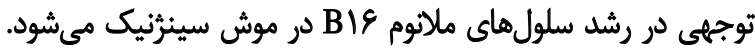

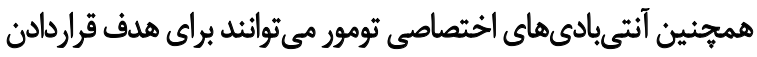

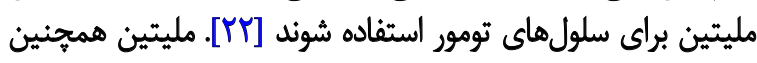

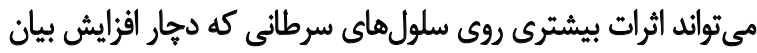

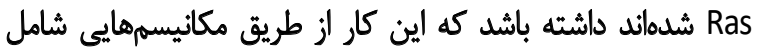

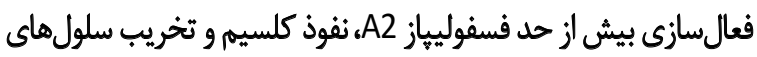

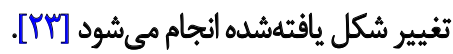

همجينين نتايج نشان ميدهد اثر مهارى مليتين روى مهاجرت

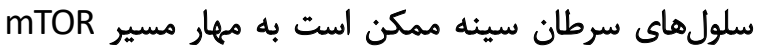

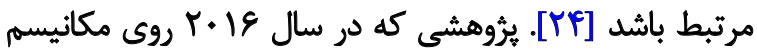

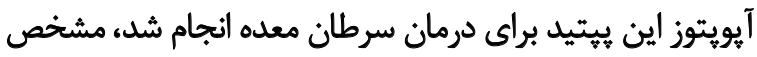

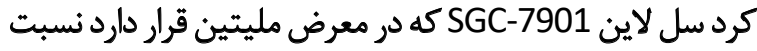

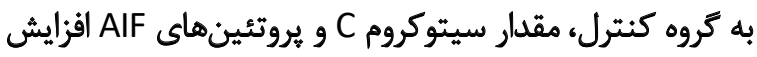

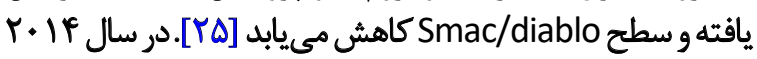

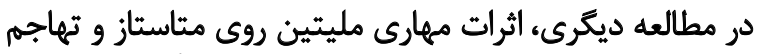

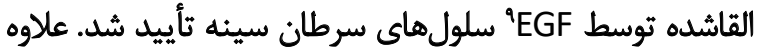

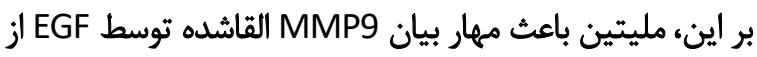

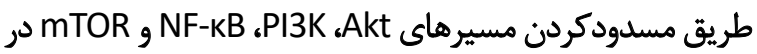

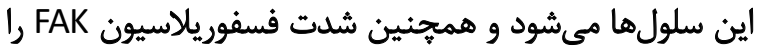

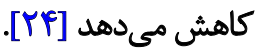

9. Epidermal Growth Factor (EGF)

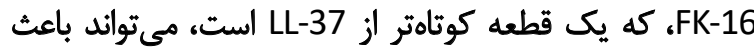

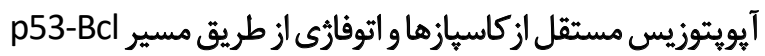

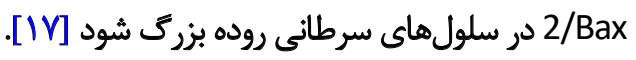

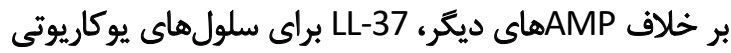

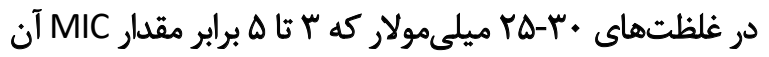

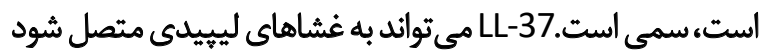

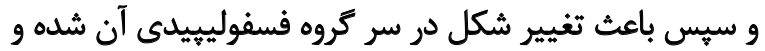

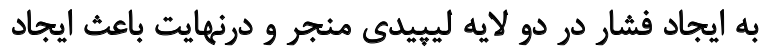

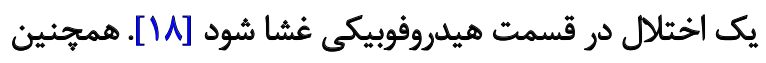

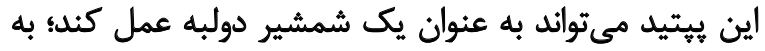

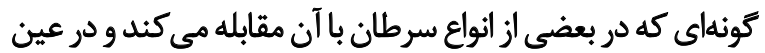

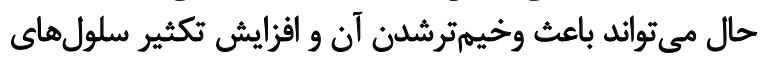

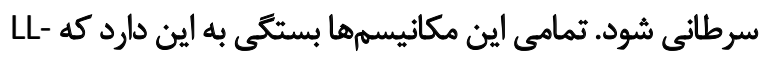
37 از جه طريقى با غشائى سلول ارتباط برقرار مي كنئ.

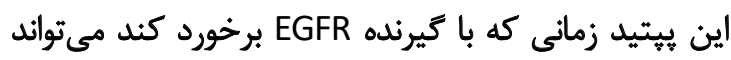

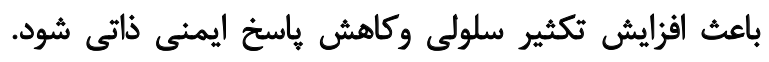

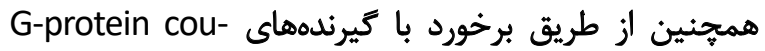

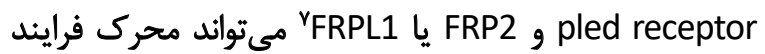

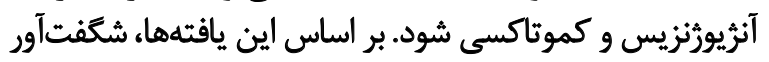

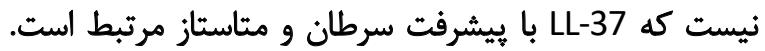

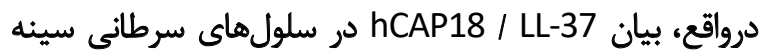

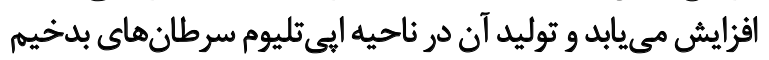

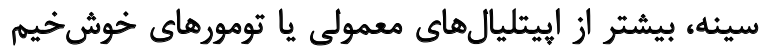

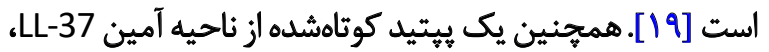

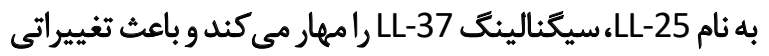
در مورفولورثى كلونى سلولهاى سرطانى مىشود.

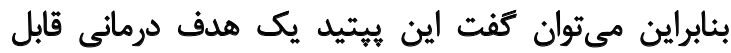

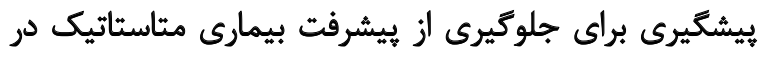

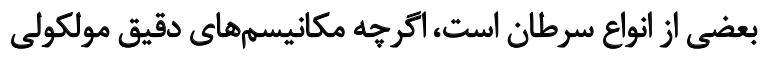

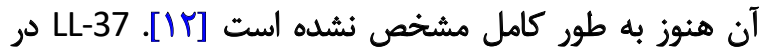

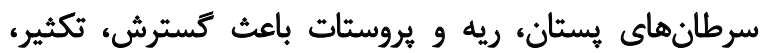

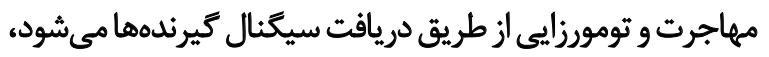

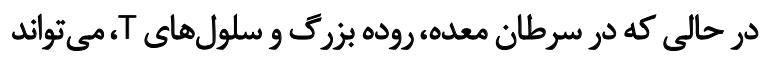
باعث توقف كسترش و منجر به فرايند مرك سلولى يعنى آيويتوز

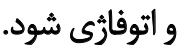

مليتين، يك يلى يبتيد محلول در آب، خطى، كاتيونى، هموليتيك

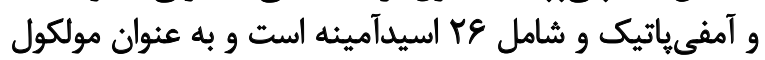

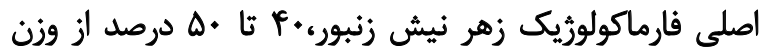

7. Formylpeptide Receptor-like 1

8. Mellitin 
"10 is

سكرويين A و B كه از همولنف يك مكس ابريشم غولييكر جدا

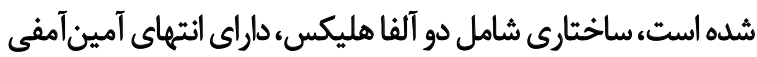

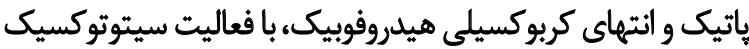

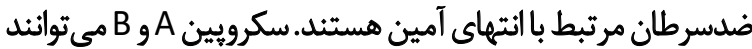

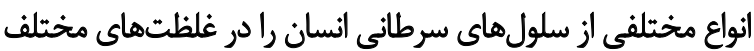

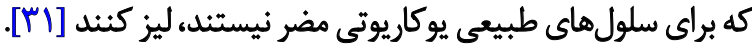

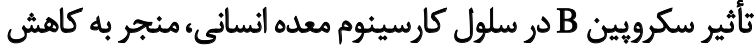

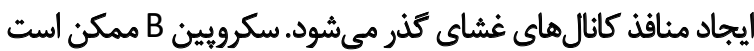

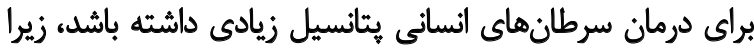

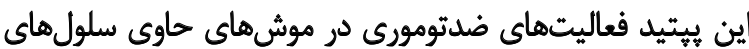

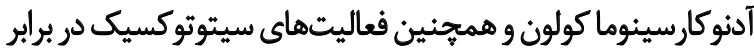
سلولهاى سرطانى تخمدان مقاوم به دارو را از خود نشان داده است. تركيب سكرويِين A و عوامل شيمىدرمانى معمولى مانند

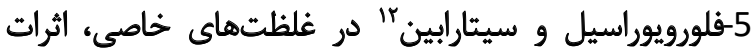

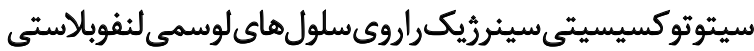

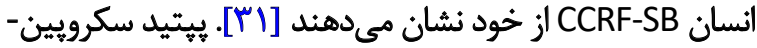

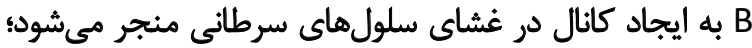

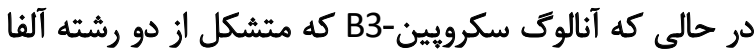

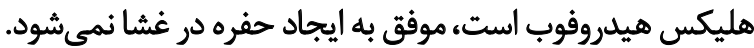

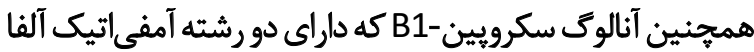

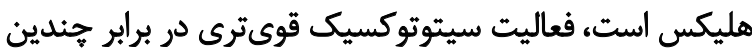

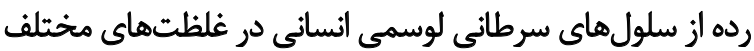

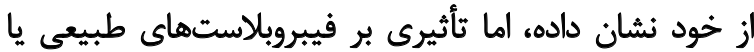
اريتروسيتهاى طبيعى انسان نداشتئد [بrان].

اين يافته ها نشان مى دهد انتهاي آمين آلفا هليكس با ويرّكى

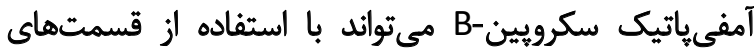

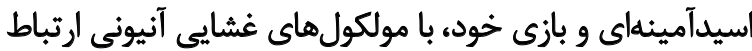

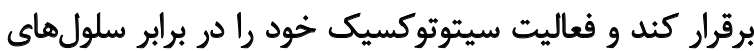

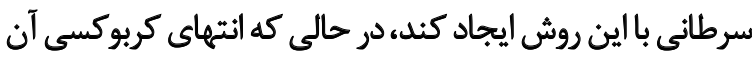

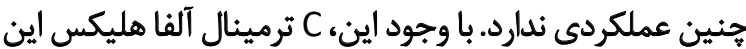

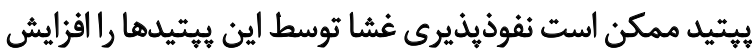

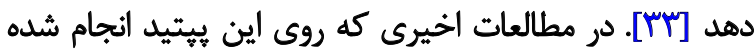

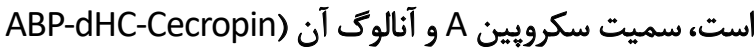

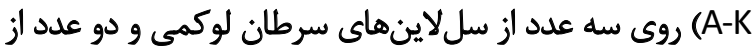

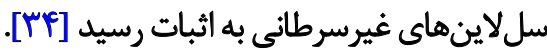

مكَينين به عنوان يك ماده سايتوتوسيك اختصاصى براى
در سال If أ r در تحقيق ديكرى كه درباره مكانيسم تأثير مليتين

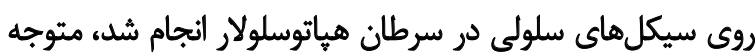

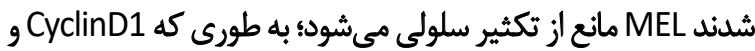

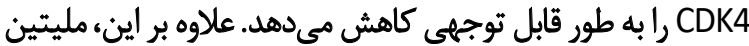

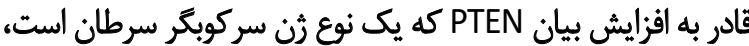
شده و در عين حال باعث تضعيف بيان هيستون داستيلاز مي مئشود.

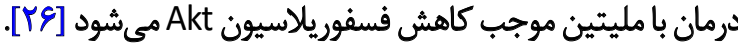

"BMAP

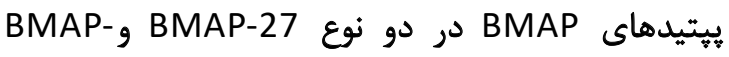

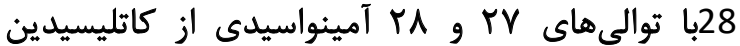

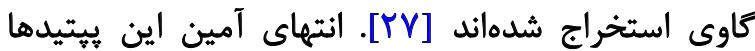

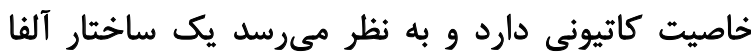

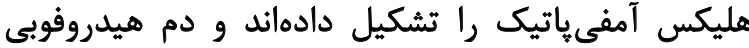
اين بيتيدها براى خاصيت سايتوتوكسيستى آن ضرورى

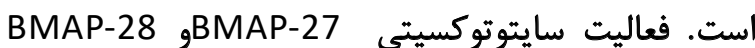

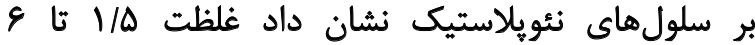

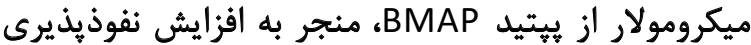

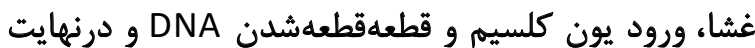

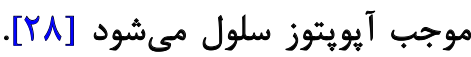
همجنين درمان با BMAP-28 در سلول هاى سرطانى انسانى

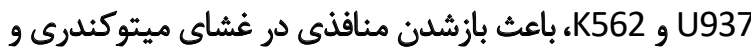

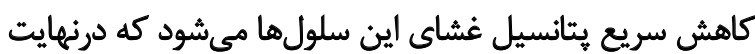

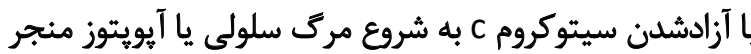

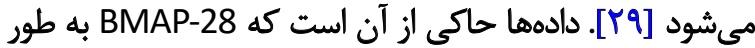

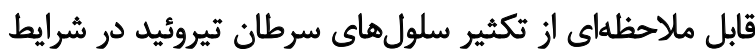

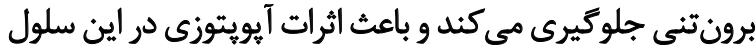

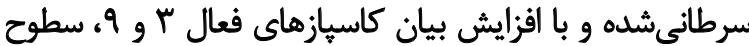

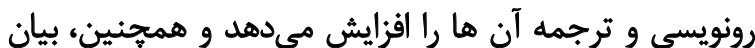

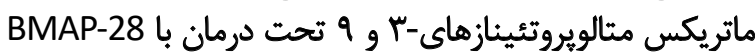

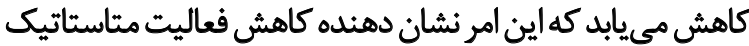

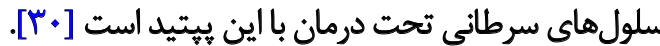
استفاده از غلظتهاى بالاتر اين يتيتيد باعث ايجاد ياسخهاي

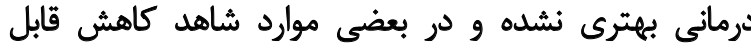

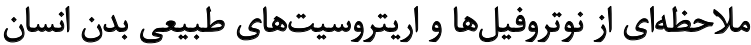

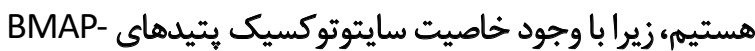

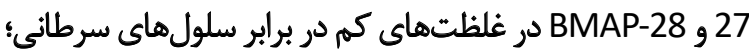
در غلظتهاى بالا براى لنفوسيتهاى فعال شده انسانى نيز داراى ناي خاصيت سميت هستئل 


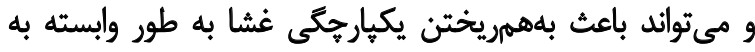

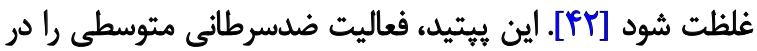

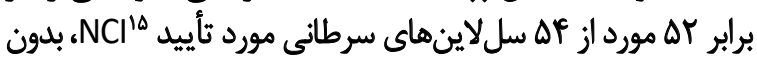

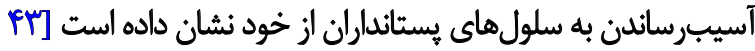

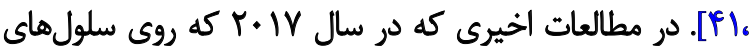

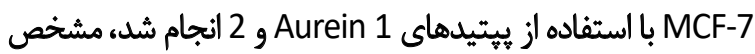

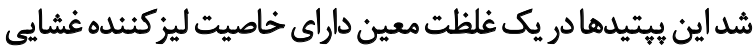

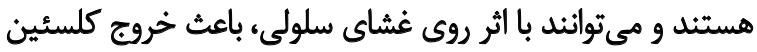

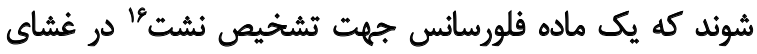

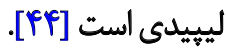
iv ungts

كاتورين كه از يوست يك قورباغه كرماي جدا مى بشود، داراي

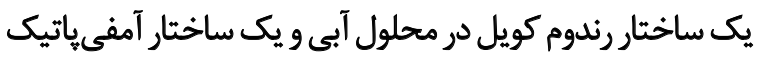
آلفاهليكال در محيطهاى غشايى است. كائورين ه ه و 9 هريك از

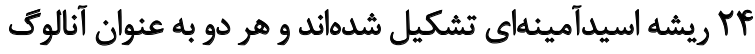

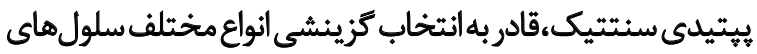

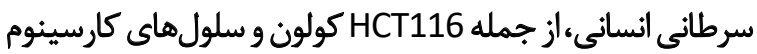

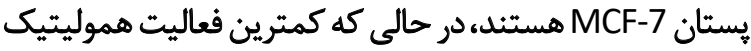

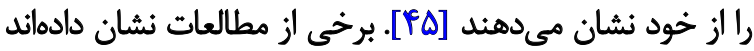

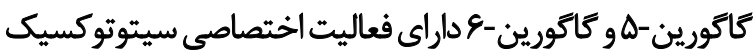

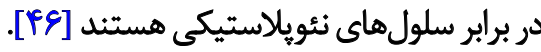

كاكورين-9 و آنالوكهاى بيتيدى و سنتيتك آن داراى طيف

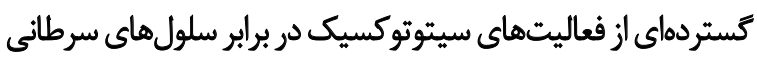

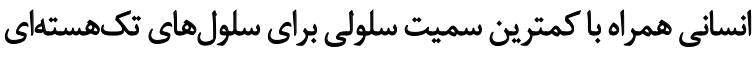

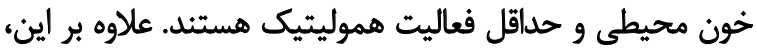

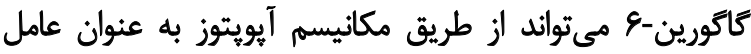

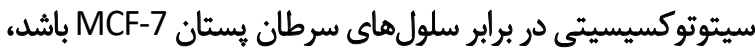

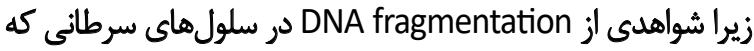

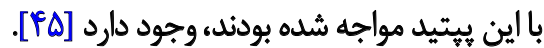

\section{ingsigs:}

بوفورين-ا يك بهيتيد وب اسيدآمينهاي است كه براي اولينبار

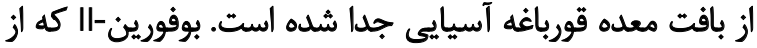

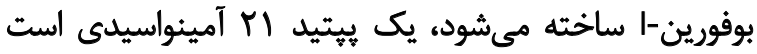

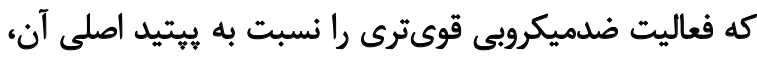

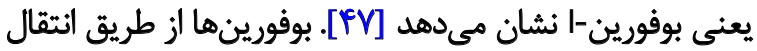

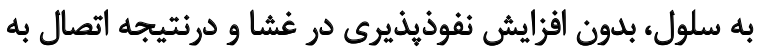

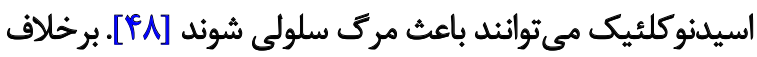

15. National Cancer Institute

16. Leakage

17. Gaegurin

18. Buforin
سلولهاى سرطانى، از يوست قورباغه ينجهاى آفريقايى جدا شده

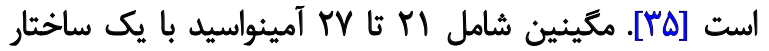

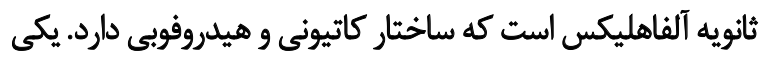

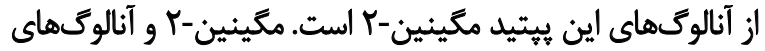

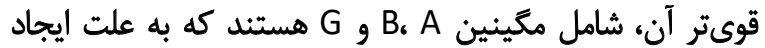

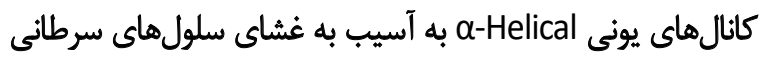

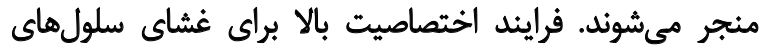
سرطانى توسط مكينين-G كشف شده است، در حالى كائى كه مكينين

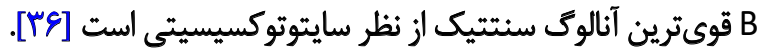

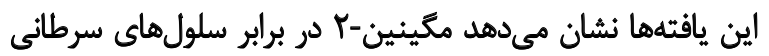

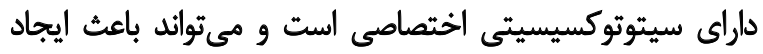

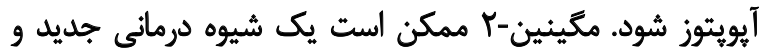
مؤثر در درمان سرطان كولون با اثرات بسيار كم سيتوتوكسيك برئ براي

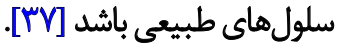

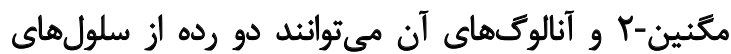

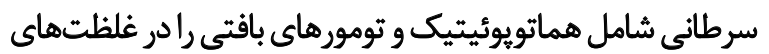

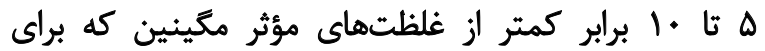

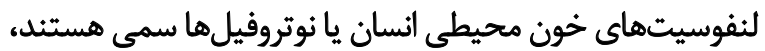

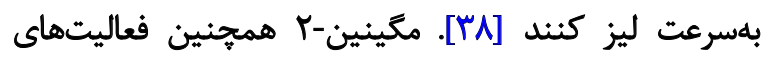

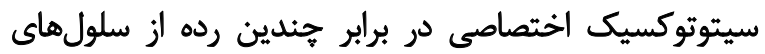

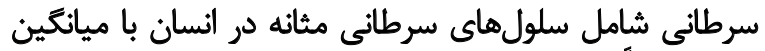

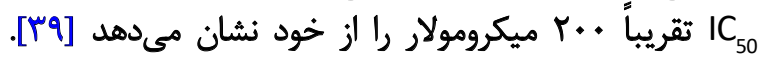

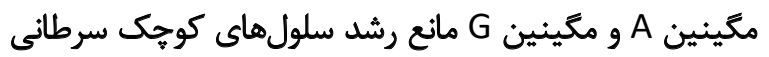

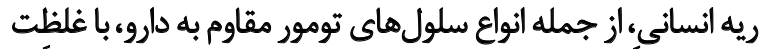
سال

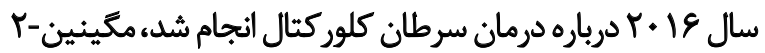
colo320 باعث جلوكيرى از زندهانداند

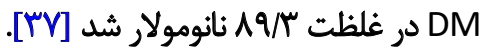

0.39

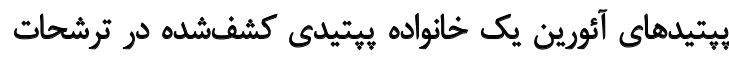

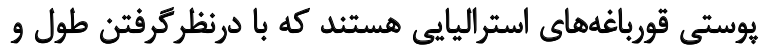

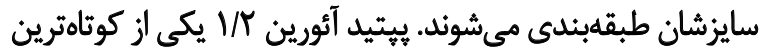

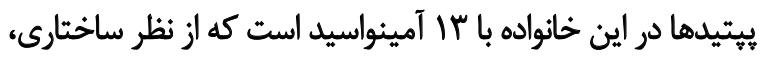

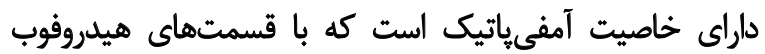
و هيدروفيلي، در امتداد محور مارييج آلفا هليكس آنهائي آنها تشكيل

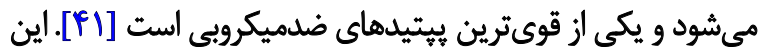

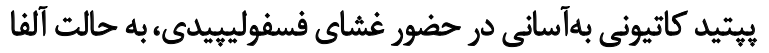

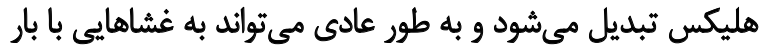

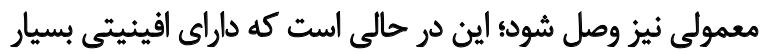

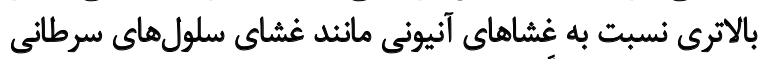

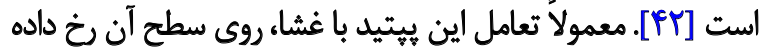




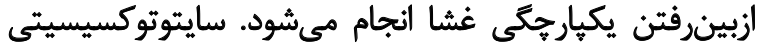

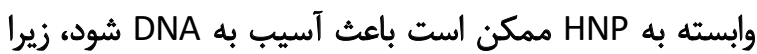

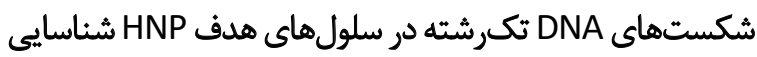

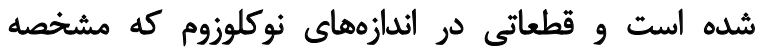

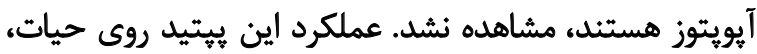

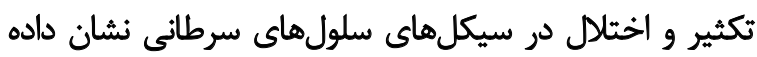

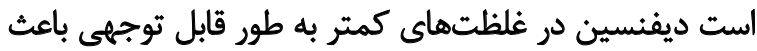

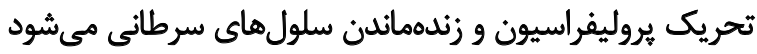

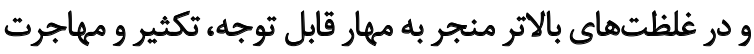

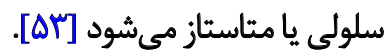

غلظتهاى بالاتر از ها ميكروكرم در ميلى ليتر از 2، 1HNP

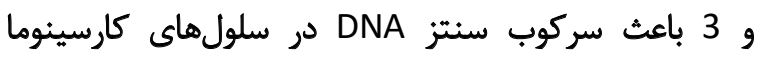

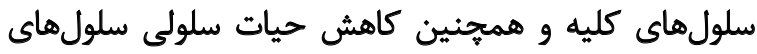

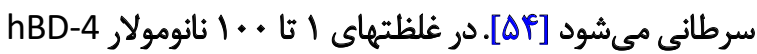

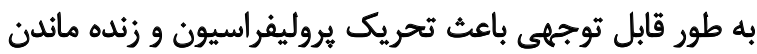

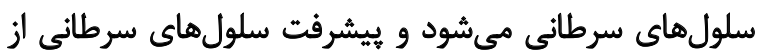

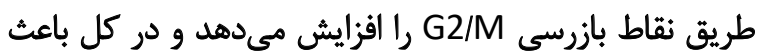

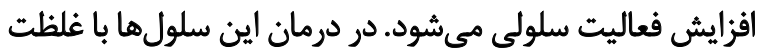

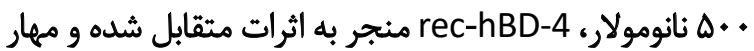

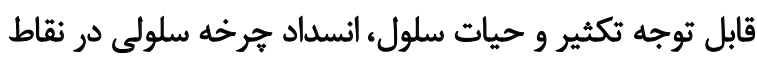

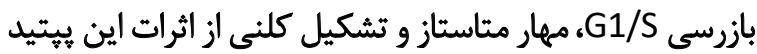

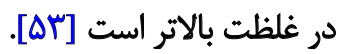

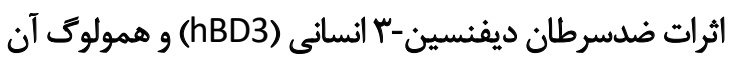

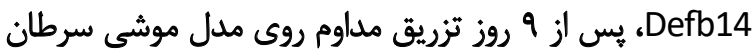

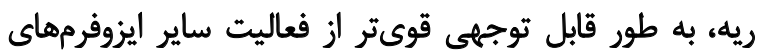

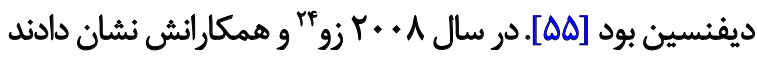

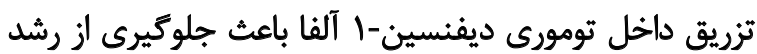

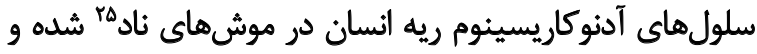
باعث آيويتوز اين سلولها مىشود [هون].

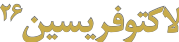

لاكتوفريسين يك AMP كاتيونى توليدشده توسط هيدروليز

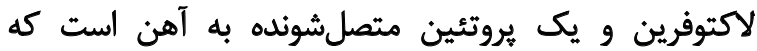

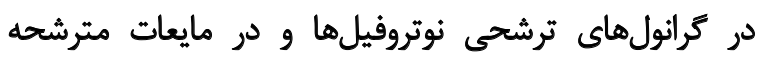

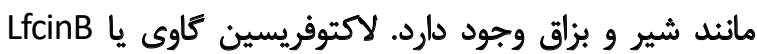

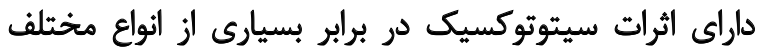

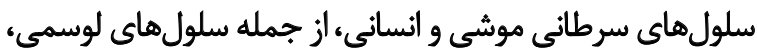

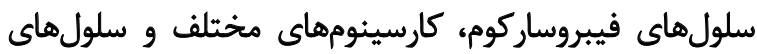

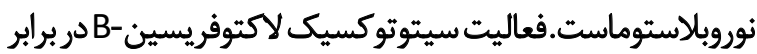
سلول هاى سرطانى به ميزان زيادى بستخى به ساختار آمفى ياتيك دريك

24. $\mathrm{Xu}$

25. Nude

26. Lactoferricin
جندين بيتيد كاتيونى ديكر، بوفورين-|| اثرات سيتوتوكسيك

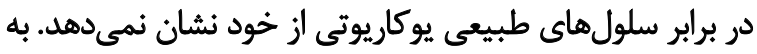

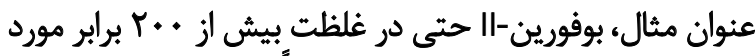

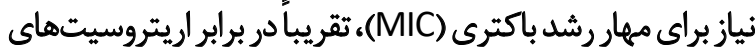

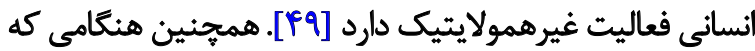

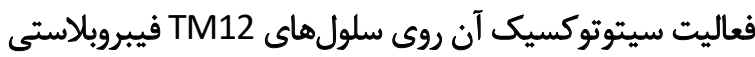

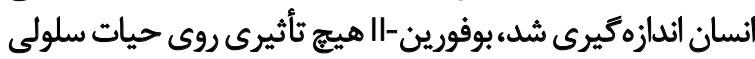

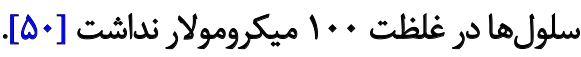

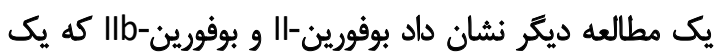

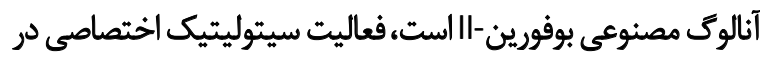

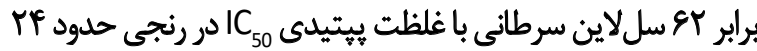

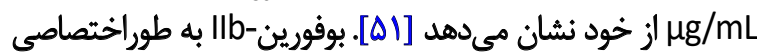

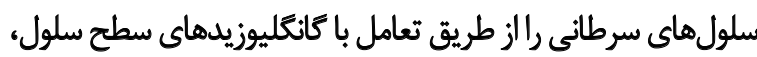

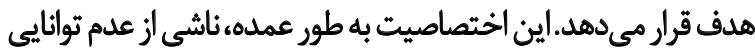

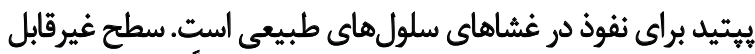

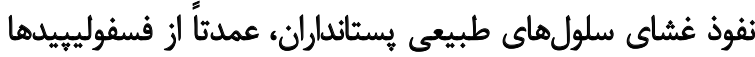

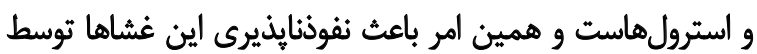

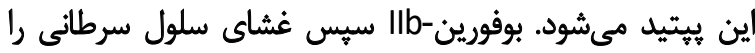

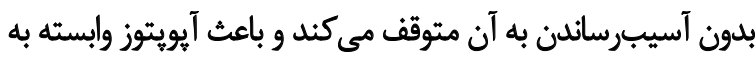

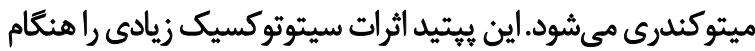

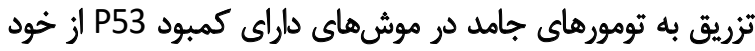

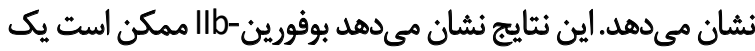

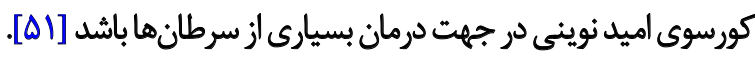

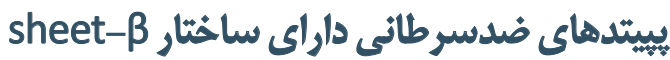

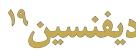

ديفنسينها گروهى از AMP هاى كاتيونى غنى از سيستئين

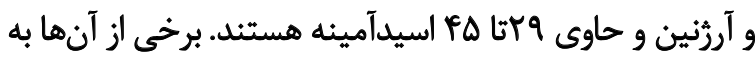

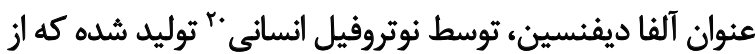

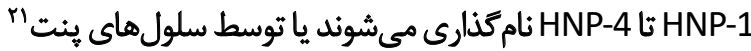

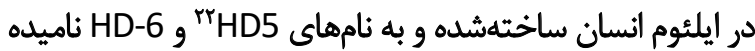

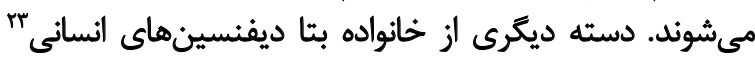

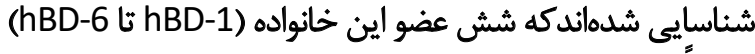

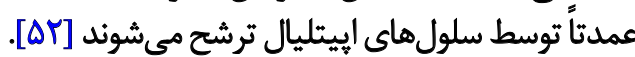

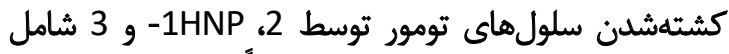

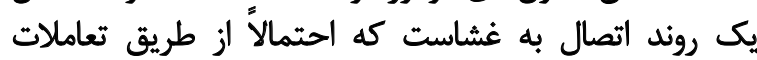

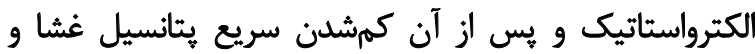

19. Defensin

20. Human Neutrophil Peptide (HNP)

21. Paneth

22. Human Defensins-5

23. Human Beta Defensins (HBD) 
دهد. آزمايشهايى نشان داد استفاده تركيبى از تاكى يلسين-ا

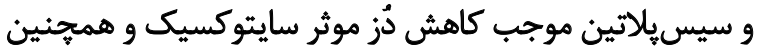

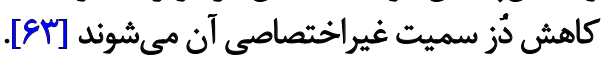

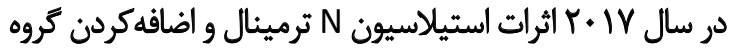

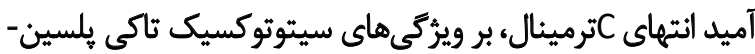

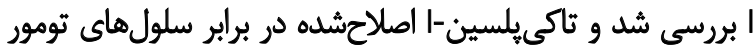

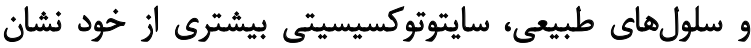

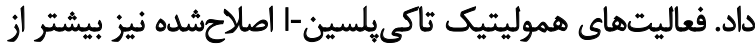

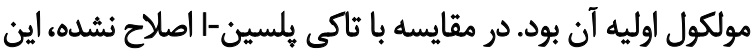

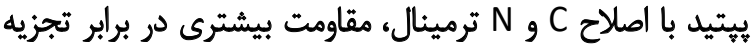

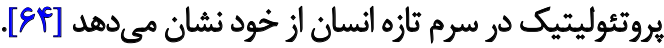

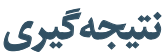

اكرجه AMP دها در جندين دهل قبل شناخته شدهاند، اما

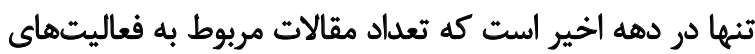

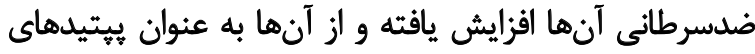

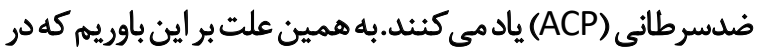

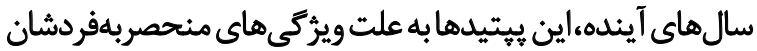

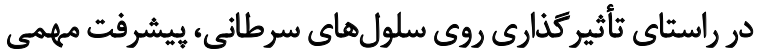

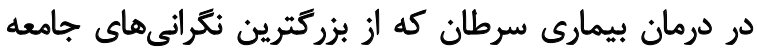

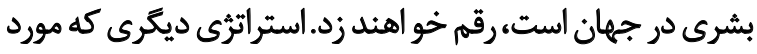

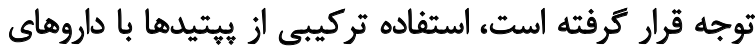

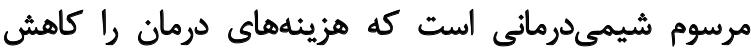

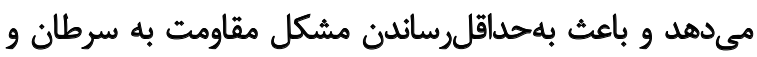

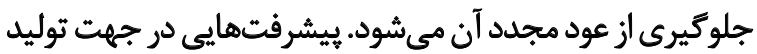

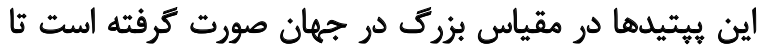

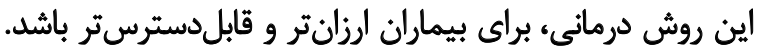

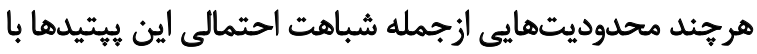

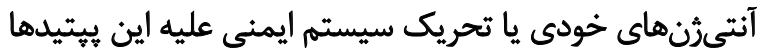

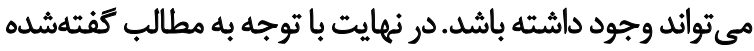

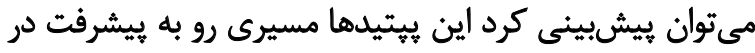

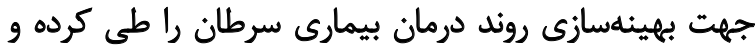
مىتواند يك روش درماني نوين و با عوارض كم ران الرائه دهند.

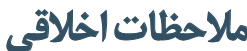

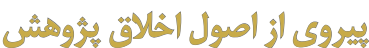

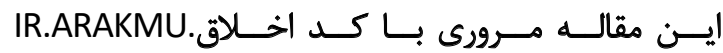

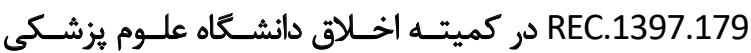

اراى ثبـت شـــه اسـت.

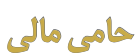

ايـن مقالـه مـرورى از حمايـت مالـى و معنــوى معاونـت
و بار مثبت خالص اين بيتيدها دارد [AV].

تحقيقاتى كه روى اين بيتيد انجام شده، نشان مى دهد مصرف

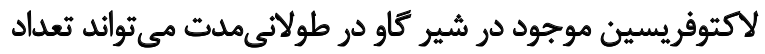

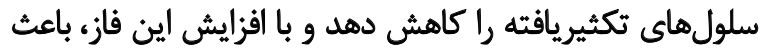

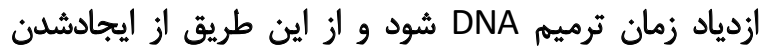

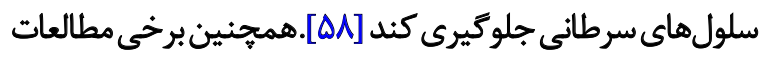

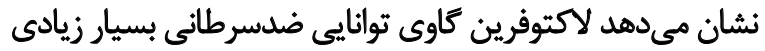
از طريق فعالسازي آبشارهاى سيكنالينك، شامل القائ بروتئينين

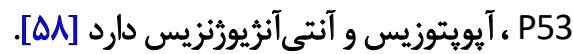

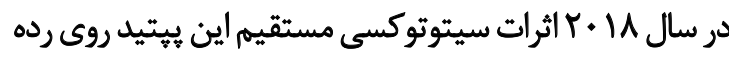

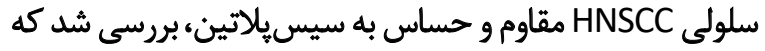

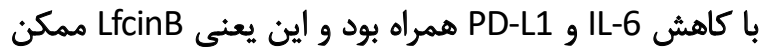

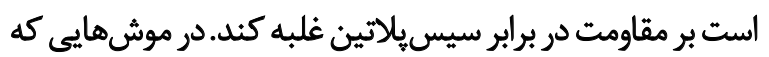

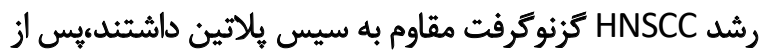

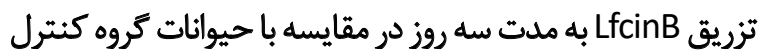

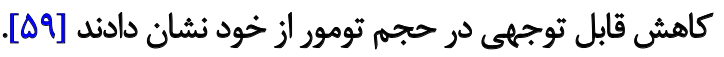

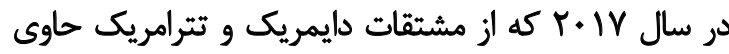

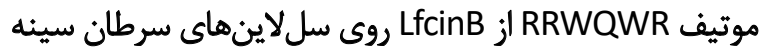
يعنى MDA-MB-468 و موتيف MDA-MB-231 استفاده كردند، در سرين

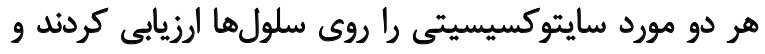

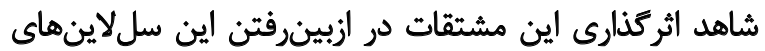

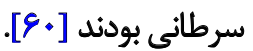

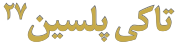

هوموسيت خركوش نعل اسبى، منبع اين AMP كاتيونى است كه

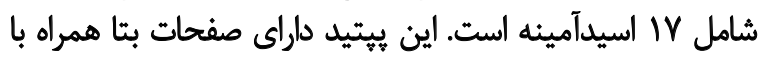

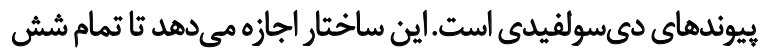

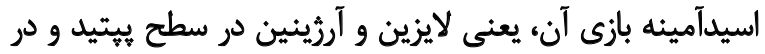

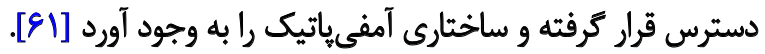

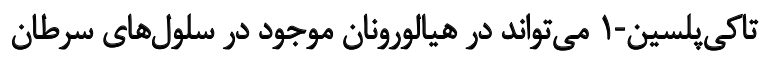

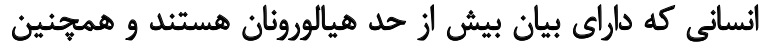

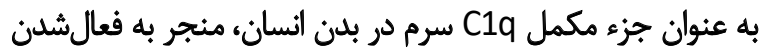

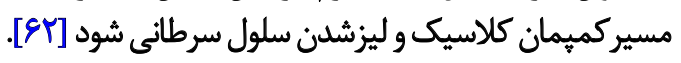
اخيراً جندين مورد مطالعه روى اين بيتيد صورث كرفته كه

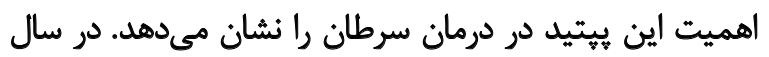

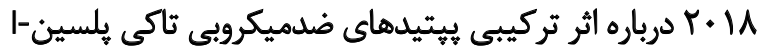

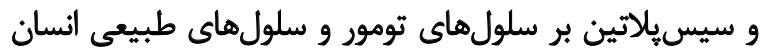

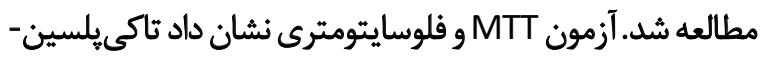

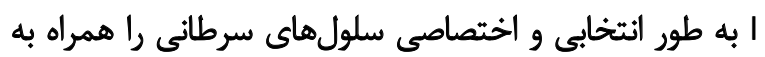
سيسيلاتين به طور وابسته به غلظت مئتوانداند تحت تأثير قرار 


$$
\begin{aligned}
& \text { تحقيقـات و فنــاورى دانشـكاه علـوم يزشـكى اراك برخـوردار } \\
& \text { بـوده استـت }
\end{aligned}
$$

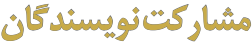

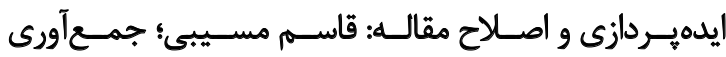

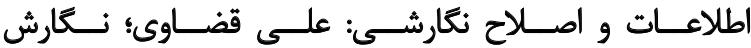

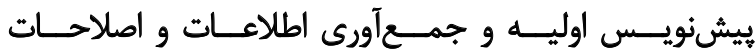

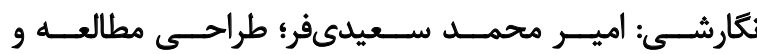

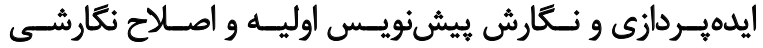

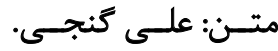

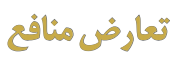

طبق نظر نويسندكان هيجَّونه تضاد منافعى در يروهش حاضر

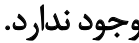

$$
\text { 管 }
$$

از كليه همكاران در معاونت تحقيقات وفناورى و مركز تحقيقات

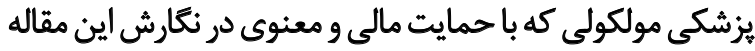

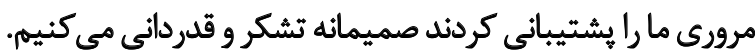




\section{References}

[1] Ferlay J, Shin HR, Bray F, Forman D, Mathers C, Parkin DM. Estimates of worldwide burden of cancer in 2008: GLOBOCAN 2008. Int J Cancer. 2010; 127(12):2893-917. [DOI:10.1002/ijc.25516] [PMID]

[2] Nourbakhsh P, Ganji A, Farahani I, Hosseinian R, Yeganefard F, Mirzaee $\mathrm{R}$, et al. Adipokine omentin-1: A diagnostic tool in breast cancer. Int J Basic Sci Med. 2018; 3(2):89-93. [DOI:10.15171/ijbsm.2018.16]

[3] Harris F, Dennison SR, Singh J, Phoenix DA. On the selectivity and efficacy of defense peptides with respect to cancer cells. Med Res Rev. 2013; 33(1):190-234. [DOI:10.1002/med.20252] [PMID]

[4] Panahi Z, Abdoli A, Mosayebi G, Mahdavi M, Bahrami F. Subcutaneous administration CpG-ODNs acts as a potent adjuvant for an HIV-1tat-based vaccine candidate to elicit cellular immunity in BALB/c mice. Biotechnol Lett. 2018; 40(3):527-33. [DOI:10.1007/s10529-017-2497-9] [PMID]

[5] Hoskin DW, Ramamoorthy A. Studies on anticancer activities of antimicrobial peptides. Biochim Biophys Acta. 2008; 1778(2):357-75. [DOI:10.1016/j.bbamem.2007.11.008] [PMID] [PMCID]

[6] Wang Z, Wang G. APD: The antimicrobial peptide database. Nucleic Acids Res. 2004; 32(suppl. 1):D590-D2. [DOI:10.1093/nar/gkh025] [PMID] [PMCID]

[7] Ejtehadifar M, Halabian R, Fooladi AAl, Ghazavi A, Mosayebi G. Anticancer effects of Staphylococcal Enterotoxin type B on U266 cells co-cultured with Mesenchymal Stem Cells. Microb Pathog. 2017; 113:438-44. [DOI:10.1016/j.micpath.2017.11.024] [PMID]

[8] Schweizer F. Cationic amphiphilic peptides with cancer-selective toxicity. Eur J Pharmacol. 2009; 625(1-3):190-4. [DOI:10.1016/j. ejphar.2009.08.043] [PMID]

[9] Chernysh S, Kim S, Bekker G, Pleskach V, Filatova N, Anikin V, et al. Antiviral and antitumor peptides from insects. Proc Natl Acad Sci. 2002; 99(20):12628-32. [DOI:10.1073/pnas.192301899] [PMID] [PMCID]

[10] Tokumaru S, Sayama K, Shirakata Y, Komatsuzawa H, Ouhara K, Hanakawa $Y$, et al. Induction of keratinocyte migration via transactivation of the epidermal growth factor receptor by the antimicrobial peptide LL-37. J Immunol. 2005; 175(7):4662-8. [DOI:10.4049/jimmunol.175.7.4662] [PMID]

[11] Weber G, Chamorro Cl, Granath F, Liljegren A, Zreika S, Saidak Z, et al. Human antimicrobial protein hCAP18/LL-37 promotes a metastatic phenotype in breast cancer. Breast Cancer Res. 2009; 11(1):R6. [DOI:10.1186/bcr2221] [PMID] [PMCID]

[12] Wang C, Tian LL, Li S, Li HB, Zhou Y, Wang H, et al. Rapid cytotoxicity of antimicrobial peptide tempoprin-1CEa in breast cancer cells through membrane destruction and intracellular calcium mechanism. PLOS One. 2013; 8(4):e60462. [DOI:10.1371/journal.pone.0060462] [PMID] [PMCID]

[13] von Haussen J, Koczulla R, Shaykhiev R, Herr C, Pinkenburg O, Reimer D, et al. The host defence peptide LL-37/hCAP-18 is a growth factor for lung cancer cells. Lung Cancer. 2008; 59(1):12-23. [DOI:10.1016/j.lungcan.2007.07.014] [PMID]

[14] Okumura K, Itoh A, Isogai E, Hirose K, Hosokawa Y, Abiko Y, et al. Cterminal domain of human CAP18 antimicrobial peptide induces apoptosis in oral squamous cell carcinoma SAS-H1 cells. Cancer lett. 2004; 212(2):185-94. [DOI:10.1016/j.canlet.2004.04.006] [PMID]

[15] Wu WKK, Sung JJY, To KF, Yu L, Li HT, Li ZJ, et al. The host defense peptide LL-37 activates the tumor-suppressing bone morphogenetic protein signaling via inhibition of proteasome in gastric cancer cells. J Cell Physiol. 2010; 223(1):178-86. [DOI:10.1002/jcp.22026] [PMID]

[16] Mader JS, Mookherjee N, Hancock RE, Bleackley RC. The human host defense peptide LL-37 induces apoptosis in a calpain-and apoptosis-inducing factor-dependent manner involving bax activity. Mol Cancer Res. 2009; 7(5):689-702. [DOI:10.1158/1541-7786.MCR-08-0274] [PMID]

[17] Ren SX, Shen J, Cheng AS, Lu L, Chan RL, Li ZJ, et al. Correction: FK-16 derived from the anticancer peptide LL-37 induces caspase-independent apoptosis and autophagic cell death in colon cancer cells. PLOS One. 2015; 10(6):e0131750. [DOI:10.1371/journal.pone.0131750] [PMID] [PMCID]

[18] Dürr UH, Sudheendra U, Ramamoorthy A. LL-37, the only human member of the cathelicidin family of antimicrobial peptides. Biochim Biophys Acta. 2006; 1758(9):1408-25. [DOI:10.1016/j.bbamem.2006.03.030] [PMID]

[19] Heilborn JD, Nilsson MF, Jimenez CIC, Sandstedt B, Borregaard N, Tham E, et al. Antimicrobial protein hCAP18/LL-37 is highly expressed in breast cancer and is a putative growth factor for epithelial cells. Int J Cancer. 2005; 114(5):713-9. [DOI:10.1002/ijc.20795] [PMID]

[20] Rady I, Siddiqui IA, Rady M, Mukhtar H. Melittin, a major peptide component of bee venom, and its conjugates in cancer therapy. Cancer Lett. 2017; 402:16-31. [DOI:10.1016/j.canlet.2017.05.010] [PMID] [PMCID]

[21] Vihinen P, Kähäri VM. Matrix metalloproteinases in cancer: Prognostic markers and therapeutic targets. Int J Cancer. 2002; 99(2):157-66. [DOI:10.1002/ijc.10329] [PMID]

[22] Russell PJ, Hewish D, Carter T, Sterling-Levis K, Ow K, Hattarki M, et al. Cytotoxic properties of immunoconjugates containing melittin-like peptide 101 against prostate cancer: In vitro and in vivo studies. Cancer Immunol Immunother. 2004; 53(5):411-21. [DOI:10.1007/s00262-0030457-9] [PMID]

[23] Sharma S. Melittin-induced hyperactivation of phospholipase A2 activity and calcium influx in ras-transformed cells. Oncogene. 1993; $8(4): 939-47$

[24] Jeong YJ, Choi Y, Shin JM, Cho HJ, Kang JH, Park KK, et al. Melittin suppresses EGF-induced cell motility and invasion by inhibiting PI3K/Akt/ mTOR signaling pathway in breast cancer cells. Food Chem Toxicol. 2014; 68:218-25. [DOI:10.1016/j.fct.2014.03.022] [PMID]

[25] Kong GM, Tao WH, Diao YL, Fang PH, Wang JJ, Bo P, et al. Melittin induces human gastric cancer cell apoptosis via activation of mitochondrial pathway. World J gastroenterology. 2016; 22(11):3186-95 [DOI:10.3748/wjg.v22.i11.3186] [PMID] [PMCID]

[26] Zhang H, Zhao B, Huang C, Meng XM, Bian EB, Li J. Melittin restore PTEN expression by down-regulating HDAC2 in human hepatocelluar carcinoma HepG2 cells. PLOS One. 2014; 9(5):e95520. [DOI:10.1371/ journal.pone.0095520] [PMID] [PMCID]

[27] Skerlavaj B, Gennaro R, Bagella L, Merluzzi L, Risso A, Zanetti M. Biological characterization of two novel cathelicidin-derived peptides and identification of structural requirements for their antimicrobial and cell Iytic activities. J Biol Chem. 1996; 271(45):28375-81. [DOI:10.1074/ jbc. 271.45.28375] [PMID]

[28] Risso A, Zanetti M, Gennaro R. Cytotoxicity and apoptosis mediated by two peptides of innate immunity. Cell Immunol. 1998; 189(2):107-15. [DOI:10.1006/cimm.1998.1358] [PMID]

[29] Risso A, Braidot E, Sordano MC, Vianello A, Macrì F, Skerlavaj B, et al. BMAP-28, an antibiotic peptide of innate immunity, induces cell death through opening of the mitochondrial permeability transition pore. 
Mol Cell Biol. 2002; 22(6):1926-35. [DOI:10.1128/MCB.22.6.19261935.2002] [PMID] [PMCID]

[30] Zhang D, Wan L, Zhang J, Liu C, Sun H. Effect of BMAP28 on human thyroid cancer TT cells is mediated by inducing apoptosis. Oncol Lett. 2015; 10(4):2620-6. [DOI:10.3892/ol.2015.3612] [PMID] [PMCID]

[31] Hui L, Leung K, Chen H. The combined effects of antibacterial peptide cecropin $A$ and anti-cancer agents on leukemia cells. Anticancer Res. 2002; 22(5):2811-6. [PMID]

[32] Srisailam S, Kumar T, Arunkumar A, Leung K, Yu C, Chen H. Crumpled structure of the custom hydrophobic lytic peptide cecropin B3. Eur J Biochem. 2001; 268(15):4278-84. [DOI:10.1046/j.14321327.2001.02345.x] [PMID]

[33] Hung SC, Wang W, Chan Sl, Chen HM. Membrane lysis by the antibacterial peptides cecropins B1 and B3: A spin-label electron spin resonance study on phospholipid bilayers. Biophys J. 1999; 77(6):3120-33. [DOI:10.1016/50006-3495(99)77142-0]

[34] Sang M, Zhang J, Zhuge Q. Selective cytotoxicity of the antibacterial peptide ABP-dHC-Cecropin A and its analog towards leukemia cells. Eur J Pharmacol. 2017; 803:138-47. [DOI:10.1016/j.ejphar.2017.03.054] [PMID]

[35] Zasloff M. Magainins, a class of antimicrobial peptides from Xenopus skin: Isolation, characterization of two active forms, and partial CDNA sequence of a precursor. Proc Natl Acad Sci USA. 1987; 84(15):5449-53. [DOI:10.1073/pnas.84.15.5449] [PMID] [PMCID]

[36] Cruciani RA, Barker JL, Zasloff M, Chen HC, Colamonici O. Antibiotic magainins exert cytolytic activity against transformed cell lines through channel formation. Proc Natl Acad Sci India Sect B Biol Sci. 1991; 88(9):3792-6. [DOI:10.1073/pnas.88.9.3792] [PMID] [PMCID]

[37] Arasu P, Ganesan N, Sivasubramanian S, Gunasekaran P. Antitumoral and apoptotic effects of magainin II against COLO 320 DM cancer cell line. International J Pharm Sci Res. 2016; 7(7):2951-8.

[38] Jacob L, Zasloff M. Potential therapeutic applications of magainins and other antimicrobial agents of animal origin. Antimicrob pept. 1994; 186:197ą223. [DOI:10.1002/9780470514658.ch12] [PMID]

[39] Lehmann J, Retz M, Sidhu SS, Suttmann H, Sell M, Paulsen F, et al. Antitumor activity of the antimicrobial peptide magainin II against bladder cancer cell lines. Eur Nourol. 2006; 50(1):141-7. [DOI:10.1016/j. eururo.2005.12.043] [PMID]

[40] Ludtke SJ, He K, Wu Y, Huang HW. Cooperative membrane insertion of magainin correlated with its cytolytic activity. Biochim Biophys Acta Biomembr. 1994; 1190(1):181-4. [DOI:10.1016/0005-2736(94)90050-7]

[41] Rozek T, Wegener KL, Bowie JH, Olver IN, Carver JA, Wallace JC, et al. The antibiotic and anticancer active aurein peptides from the Australian Bell Frogs Litoria aurea and Litoria raniformis: The solution structure of aurein 1.2. Eur J Biochemistry. 2000; 267(17):5330-41. [DOI:10.1046/ j.1432-1327.2000.01536.x] [PMID]

[42] Shahmiri M, Enciso M, Mechler A. Controls and constrains of the membrane disrupting action of Aurein 1.2. Sci Rep. 2015; 5:16378. [DOI:10.1038/srep16378] [PMID] [PMCID]

[43] Laadhari M, Arnold AA, Gravel AE, Separovic F, Marcotte I. Interaction of the antimicrobial peptides caerin 1.1 and aurein 1.2 with intact bacteria by $2 \mathrm{H}$ solid-state NMR. Biochim Biophys Acta Biomembr. 2016; 1858(12):2959-64. [DOI:10.1016/j.bbamem.2016.09.009] [PMID]

[44] Armbrecht L, Gabernet G, Kurth F, Hiss JA, Schneider G, Dittrich PS. Characterisation of anticancer peptides at the single-cell level. Lab on a Chip. 2017; 17(17):2933-40. [DOI:10.1039/C7LC00505A] [PMID] [PMCID]

[45] Kim S, Kim SS, Bang YJ, Kim SJ, Lee BJ. In vitro activities of native and designed peptide antibiotics against drug sensitive and resistant tumor cell lines. Peptides. 2003; 24(7):945-53. [DOI:10.1016/S01969781(03)00194-3]

[46] Won HS, Seo MD, Jung SJ, Lee SJ, Kang SJ, Son WS, et al. Structural determinants for the membrane interaction of novel bioactive undecapeptides derived from gaegurin 5. J med Chem. 2006; 49(16):4886-95 [DOI:10.1021/jm050996u] [PMID]

[47] Park CB, Kim MS, Kim SC. A novel antimicrobial peptide frombufo bufo gargarizans. Biochem Biophys Res Commun. 1996; 218(1):408-13. [DOI:10.1006/bbrc.1996.0071] [PMID]

[48] Park CB, Kim HS, Kim SC. Mechanism of action of the antimicrobial peptide buforin II: buforin II kills microorganisms by penetrating the cell membrane and inhibiting cellular functions. Biochem Biophys Res Commun. 1998; 244(1):253-7. [DOI:10.1006/bbrc.1998.8159] [PMID]

[49] Kobayashi S, Takeshima K, Park CB, Kim SC, Matsuzaki K. Interactions of the novel antimicrobial peptide buforin 2 with lipid bilayers: Proline as a translocation promoting factor. Biochem. 2000; 39(29):8648-54. [DOI:10.1021/bi0004549] [PMID]

[50] Takeshima K, Chikushi A, Lee KK, Yonehara S, Matsuzaki K. Translocation of analogues of the antimicrobial peptides magainin and buforin across human cell membranes. J Biol Chem. 2003; 278(2):1310-5. [DOI:10.1074/jbc.M208762200] [PMID]

[51] Lee HS, Park CB, Kim JM, Jang SA, Park IY, Kim MS, et al. Mechanism of anticancer activity of buforin $\mathrm{llb}$, a histone $\mathrm{H} 2 \mathrm{~A}$-derived peptide. Cancer lett. 2008; 271(1):47-55. [DOI:10.1016/S0304-3835(98)00189-X] [PMID]

[52] Ganz T. Defensins and other antimicrobial peptides: a historical perspective and an update. Comb Chem High Throughput Screen. 2005 8(3):209-17. [DOI:10.2174/1386207053764594]

[53] Gerashchenko O, Zhuravel E, Skachkova O, Khranovska N, Filonenko $V$, Pogrebnoy P, et al. Biologic activities of recombinant human-beta-defensin-4 toward cultured human cancer cells. Exp Oncol. 2013; 35(2):7682. [PMID]

[54] Müller CA, Markovic-Lipkovski J, Klatt T, Gamper J, Schwarz G, Beck H et al. Human $\alpha$-defensins HNPs-1,-2, and-3 in renal cell carcinoma: Influences on tumor cell proliferation. Am J Pathol. 2002; 160(4):1311-24. [DOI:10.1016/S0002-9440(10)62558-8]

[55] Hanaoka Y, Yamaguchi Y, Yamamoto H, Ishii M, Nagase T, Kurihara $H$, et al. In vitro and In vivo anticancer activity of human $\beta$-Defensin-3 and its mouse homolog. Anticancer Res. 2016; 36(11):5999-6004. [DOI:10.21873/anticanres.11188] [PMID]

[56] Xu N, Wang YS, Pan WB, Xiao B, Wen YJ, Chen XC, et al. Human $\alpha$-defensin- 1 inhibits growth of human lung adenocarcinoma xenograft in nude mice. Mol Cancer Ther. 2008; 7(6):1588-97. [DOI:10.1158/15357163.MCT-08-0010] [PMID]

[57] Hunter $\mathrm{H}$, Vogel H. Laetoferriein: A lactoferfindeefive peptide with an timierobial, antiviral, antitumor an d immunological properties. Cell Mo Life Sei. 2005; 62:2588-98. [DOI:10.1007/s00018-005-5373-z] [PMID]

[58] Freiburghaus C, Janicke B, Lindmark-Månsson $\mathrm{H}$, Oredsson S, Paulsson $\mathrm{M}$. Lactoferricin treatment decreases the rate of cell proliferation of a human colon cancer cell line. J Dairy Sci. 2009; 92(6):2477-84. [DOI:10.3168/jds.2008-1851] [PMID] 
[59] Zhang P, Liu J, Li W, Li S, Han X. Lactoferricin B reverses cisplatin resistance in head and neck squamous cell carcinoma cells through targeting PD-L1. Cancer Med. 2018; 7(7):3178-87. [DOI:10.1002/cam4.1529] [PMID] [PMCID]

[60] Vargas Casanova Y, Rodríguez Guerra JA, Umaña Pérez YA, Leal Castro AL, Almanzar Reina G, García Castañeda JE, et al. Antibacterial synthetic peptides derived from bovine lactoferricin exhibit cytotoxic effect against MDA-MB-468 and MDA-MB-231 breast cancer cell lines. Mol. 2017; 22(10):1641. [DOI:10.3390/molecules22101641] [PMID] [PMCID]

[61] Rao AG. Conformation and antimicrobial activity of linear derivatives of tachyplesin lacking disulfide bonds. Arch Biochem Biophys. 1999; 361(1):127-34. [DOI:10.1006/abbi.1998.0962] [PMID]

[62] Chen J, Xu XM, Underhill CB, Yang S, Wang L, Chen Y, et al. Tachyplesin activates the classic complement pathway to kill tumor cells. Cancer Res. 2005; 65(11):4614-22. [DOI:10.1158/0008-5472.CAN-04-2253] [PMID]

[63] Kuzmin D, Emel'yanova A, Kalashnikova M, Panteleev P, Ovchinnikova T. In Vitro Study of Antitumor Effect of Antimicrobial Peptide Tachyplesin I in Combination with Cisplatin. Bull Exp Biol Med. 2018; 165(2):220-4. [DOI:10.1007/s10517-018-4134-6] [PMID]

[64] Kuzmin D, Emelianova A, Kalashnikova M, Panteleev P, Ovchinnikova $\mathrm{T}$. Effect of $\mathrm{N}$-and $\mathrm{C}$-terminal modifications on cytotoxic properties of antimicrobial peptide tachyplesin I. Bull Exp Biol Med. 2017; 162(6):7547. [DOI:10.1007/s10517-017-3705-2] [PMID] 